\title{
Contribuição ao conhecimento da biologia do peixe-rei, Xenomelaniris brasiliensis (Quoy \& Gaimard, 1824) (Atherinidae), no complexo baía-estuário de Santos e São Vicente, Brasil
}

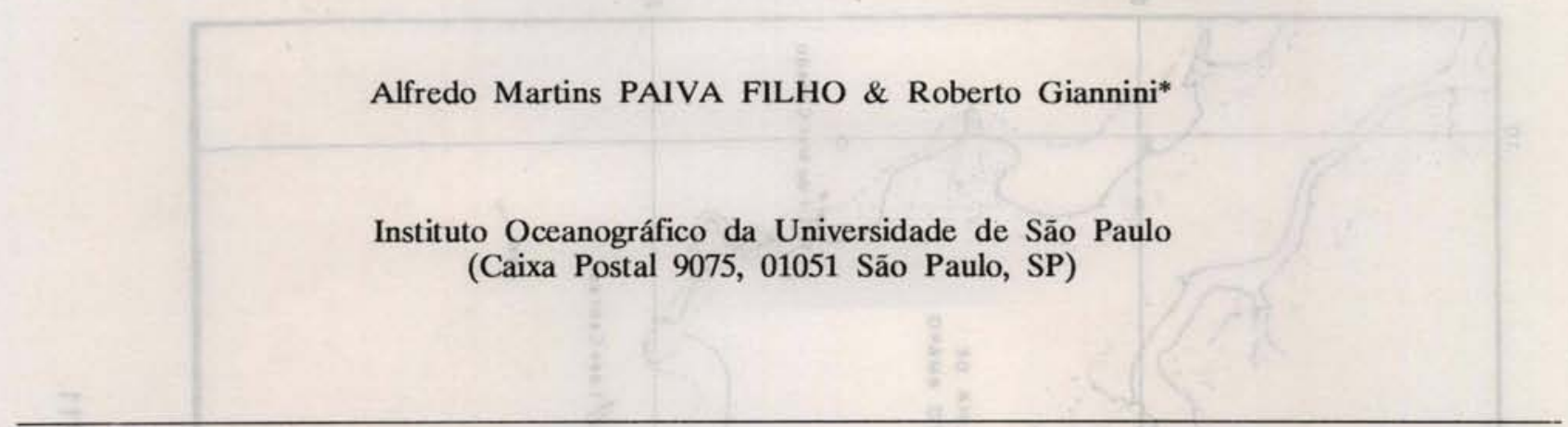

\section{Introdução}

O peixe-rei Xenomelaniris brasiliensis é uma espécie de pequeno porte, atingindo no máximo $160 \mathrm{~mm}$ de comprimento total, com distribuição da Venezuela ao Brasil (Rio Grande do Sul) e ocorrendo principalmente na desembocadura de rios e em águas salobras (Figueiredo \& Menezes, 1978).

Alimentam-se de zooplâncton quando juvenis e de organismos bentônicos da infauna e epifauna quando adultos (Carvalho, 1953; Bemvenuti, 1984).

Embora não seja eficientemente capturada na pesca artesanal, em virtude da seletividade do aparelho de pesca utilizado, $X$. brasiliensis é uma das espécies mais abundantes em arrastos de praia costeiros e estuarinos no litoral sudeste-sul do Brasil (Bemvenuti, 1984; Chao et al., 1985, Paiva Filho et al., 1987).

No complexo baía-estuário de Santos e Sāo Vicente foi freqüente e abundante nos arrastos de praia,

(*) Pós-graduando do Departamento de Oceanografia Biológica. Contr. $n^{\circ} 711$ do Inst. oceanogr. da Usp. correspondendo a mais de $30 \%$ da captura total no estuário de São Vicente (Paiva Filho et al., op.cit.; Paiva Filho \& Toscano, 1987).

Neste trabalho foram analisados a ocorrência, o crescimento, a relaçāo peso/comprimento, o fator de condição e características merísticas e morfométricas.

\section{Material e métodos}

A área estudada compreende as praias adjacentes às baías e estuários de Santos e de São Vicente (Fig. 1). O material analisado constou de doze amostras mensais coletadas entre dezembro de 1984 e novembro de 1985 , num total de 2.632 exemplares.

As amostras foram obtidas com arrastos de praia realizados paralelamente à linha de costa, em profundidade inferior a $1,5 \mathrm{~m}$, com uma rede de calão de $15,0 \mathrm{~m}$ de comprimento, $1,5 \mathrm{~m}$ de altura e $5 \mathrm{~mm}$ de malha (nó a nó); mensalmente foram efetuados em média três arrastos, cobrindo uma distância de cerca de $150 \mathrm{~m}$ no total. 


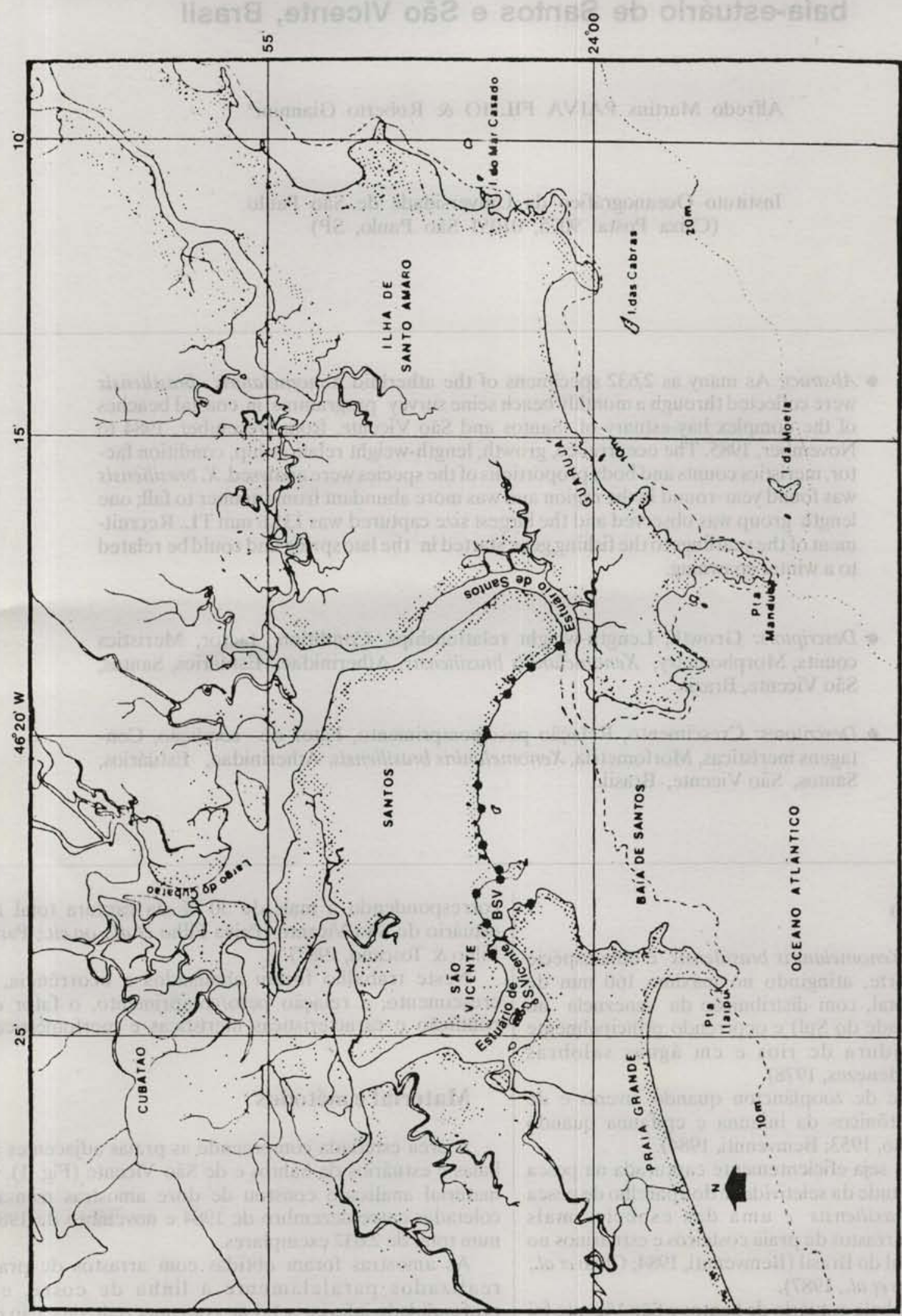

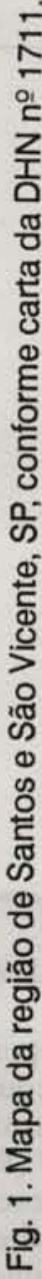


Os exemplares foram conservados em gelo e, em laboratório, foram considerados os dados relativos aos seguintes caracteres:

- peso total (PT) - obtido de cada exemplar em balança eletrônica (precisão de $0,1 \mathrm{~g}$ ).

\section{Medidas morfométricas (Fig. 2)}

- comprimento total (CT) -medida horizontal da ponta do focinho à extremidade da nadadeira caudal levemente distendida;

- comprimento da cabeça (CCa) - medida horizontal da ponta do focinho à extremidade máxima da membrana opercular;

- comprimento do focinho ( $\mathrm{CFo}$ ) - medida horizontal da ponta do focinho à margem anterior da órbita;

- comprimento da maxila superior (CMS) - medida da sínfese pré-maxilar à extremidade posterior do maxilar;

- diâmetro do olho(DO) - distância horizontal entre as margens anterior e posterior da órbita;

- distância pré-dorsal (DDo) - medida horizontal da ponta do focinho à origem da primeira nadadeira dorsal;

- distância pré-ventral (DVe) - medida horizontal da ponta do focinho à origem da nadadeira ventral;

- distância pré-peitoral (DPe) - medida horizontal da ponta do focinho à origem da nadadeira peitoral;

- distância pré-anal (DAn) - medida horizontal da ponta do focinho à origem da nadadeira anal;

- altura do corpo (AC) - medida vertical entre o dorso e o abdomen, na altura da origem da primeira nadadeira dorsal;

- altura do pedúnculo caudal (APC) - medida vertical da menor altura do pedúnculo caudal;

\section{Caracteres merísticos}

- número de rastros branquiais (NRB) - contagem do número de rastros do primeiro arco branquial esquerdo, incluindo-se os rudimentos;

- número de escamas (NE) - contagem da série de escamas entre a margem superior do opérculo à base da nadadeira caudal.

As medidas referentes aos caracteres morfométricos foram tomadas com o auxilio de um paquímetro com precisāo de $0,1 \mathrm{~mm}$, e as contagens foram realizadas sob estereomicroscópio. Foi obtida a curva de captura por unidade de esforço (CPUE) por mês, para todo o período de coleta (Fig. 3A).

As curvas da distribuição da freqüência relativa do comprimento total para todo o período (Fig. 3B) e por mês (Fig. $3 \mathrm{C}$ ), foram obtidas através do grupamento dos indivíduos em classes de $5 \mathrm{~mm}$ de comprimento total (CT); foi calculada a média (X) com intervalo de $95 \%$ de confiança, apresentada juntamente com os valores máximo (XM) e mínimo (xm).

O estudo da relação peso total/comprimento total dos exemplares, foi analisado para todo o período; após inspeção gráfica e transformação logarítmica, aos dados foram ajustadas equaçōes de retas pelo método dos mínimos quadrados (Fig. 4A).

Calculou-se o fator de condição médio $(\mathrm{K})$ por mês (Fig. 4B) e por estação do ano (Fig. 4D) e o comprimento médio (X) dos exemplares por mês (Fig. 4C), os quais foram lançados em gráficos contra o tempo.

Para a análise dos caracteres merísticos foram utilizados dados de 256 exemplares; para cada caráter merístico foi obtida a distribuição de freqüência absoluta e foi calculada a média (X) com intervalo de $95 \%$ de

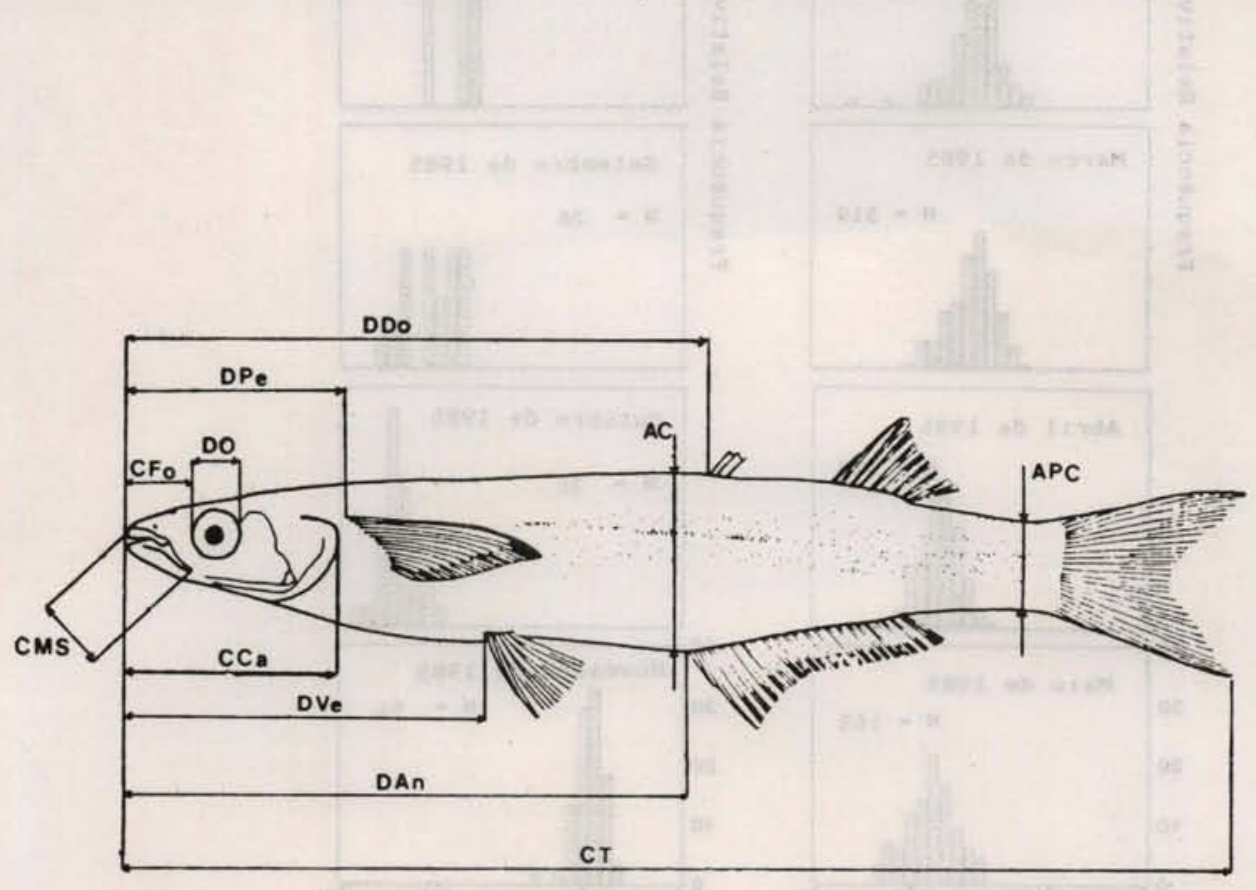

Fig. 2. Esquema indicativo dos pontos de referência para medida dos caracteres morfométricos considerados em Xenomelaniris brasiliensis. 

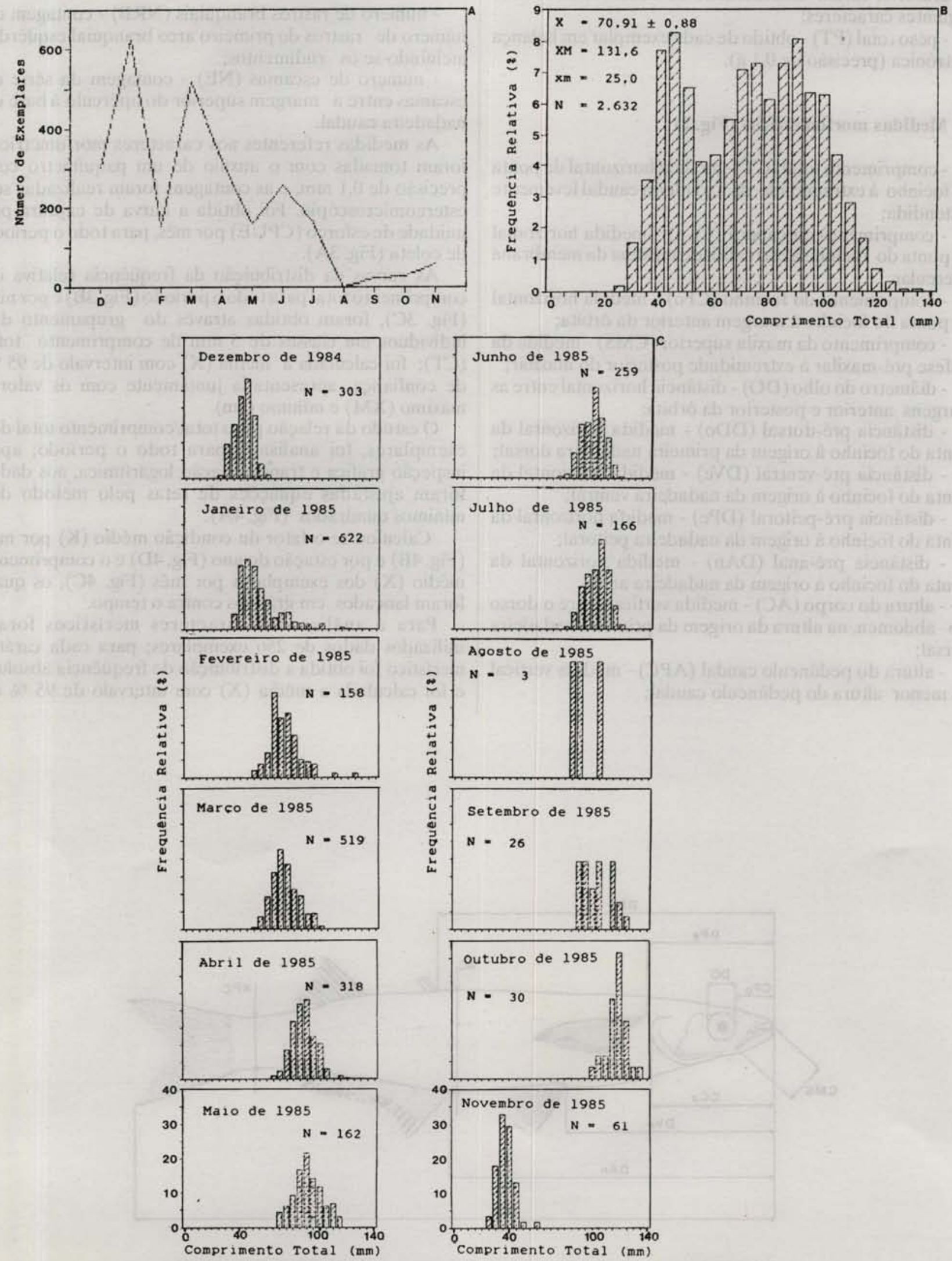

Fig. 3. Captura por unidade de esforço (A), distribuição total $(B)$ e mensal $(C)$ da frequeência relativa $(\%)$ por classes de comprimento total $(5 \mathrm{~mm})$, para todo o período e sexos grupados. $\mathrm{N}=$ número de exemplares capturados e medidos; $X=$ média \pm intervalo de $95 \%$ de confiança; $X M$ e xm $=$ comprimento do maior e do menor exemplares capturados 
confiança, apresentada juntamente com os valores máximo (XM) e mínimo (xm) (Figs 4E e 4F).

Para a análise dos caracteres morfométricos foram utilizados 517 exemplares; os dados considerados com os respectivos valores máximo (XM), mínimo (xm), média (X) e desvio padrão (dp), foram especificados na Tabela 1.

Tais dados foram então lançados em gráficos, considerando- se os elementos do corpo em relação ao comprimento total, e os elementos da cabeça em relação ao comprimento da cabeça (Fig. 5); a inspeção gráfica mostrou a existência de linearidade, no intervalo de comprimento considerado, e aos dados foram ajustadas equaçōes de retas pelo método dos mínimos quadrados.

\section{Resultados e discussão}

\section{Ocorrência e crescimento}

$X$. brasiliensis ocorreu durante o ano todo na região, com maior abundância nos meses de verão e outono (Fig. 3A), e a entrada dos jovens do ano ocorreu a partir de novembro (Fig. 3C); foi verificada uma distribuição de comprimentos unimodal com amplitude entre 25 e 131,6 mm (Fig. 3B).

A maior abundância dos jovens do ano entre o verão $\mathrm{e}$ o outono (maiores temperaturas) estão de acordo com o observado por Paiva Filho \& Toscano (1987), os quais encontraram também uma correlação positiva entre a abundância dessa espécie e a temperatura da água; para a população da Lagoa dos Patos (RS), os picos de abundância ocorreram no outono e inverno, resultantes de uma desova de verão (Bemvenuti, 1984).

Pelas Figuras $3 \mathrm{C}$ e $4 \mathrm{C}$ foi possível acompanhar, através do deslocamento da moda e do comprimento médio, o crescimento dos indivíduos na região; a aparente homogeneidade entre as modas nos meses de agosto e setembro, bem como a pequena queda do comprimento médio associado com uma maior amplitude desse valor esteve relacionada ao reduzido número de exemplares capturados nesse período (Fig. 3A).

A brusca queda do valor do comprimento médio no mês de novembro (Fig. 4C) refletiu o início do recrutamento da espécie à arte de pesca empregada, resultado este distinto do proposto por Bemvenuti (op.cit.), para quem a espécie foi recrutada na Lagoa dos Patos (RS) a partir do verâo (quando ocorrem temperaturas mais favoráveis ao desenvolvimento das larvas e jovens do ano), junto às áreas mais internas da região estuarina.

O desaparecimento dos maiores indivíduos (classe de $130 \mathrm{~mm}$ ) verificado no mês de novembro bem como a presença de uma única classe modal se deslocando ao longo do tempo (Fig. $3 \mathrm{C}$ ) poderia indicar que ao final de um ano os indivíduos abandonaram a regiāo de estudo, devido a um padrâo de deslocamento reprodutivo; o deslocamento de exemplares adultos ao interior da regiảo estuarina na época da desova e seu retorno à desembocadura após a mesma foi relatado por Bemvenuti (op.cit.) para a espécie na Lagoa dos Patos (RS). Novos programas de amostragem foram realizados no complexo baía-estuário de Santos e São Vicente, procurando elucidar o padrão de deslocamento do peixe-rei, sendo que os resultados serão abordados em trabalhos futuros.

\section{Relação peso/comprimento e fator de condição}

Com a análise dos dados de peso e comprimento, foi representada a relação peso/comprimento pela seguinte equação (Fig. 4A):

$$
\text { PT }=5,651 \times 10^{-6} \mathrm{CT}^{3,036} \text { com } \mathrm{r}=0,99 \text { e p } 0,01 \text {, }
$$

onde

PT representa o peso, CT o comprimento e $\mathrm{r}$ o coeficiente de correlaçāo linear de Pearson.

O fator de condição $(\mathrm{K})$ em peixes se altera com variações ambientais e condições de nutrição dos indivíduos, sendo conhecidas suas flutuações durante o ciclo reprodutivo (Vazzoler \& Vazzoler, 1965; Isaac-Nahum \& Vazzoler, 1983); em geral, os valores máximos coincidem com o período de maior ocorrência de exemplares com ovários maturos (estádio C) e os menores valores estão relacionados com a maior freqüência de ovários esvaziados (estádio D).

Neste trabalho, após constatada a independência do fator de condição com o comprimento dos exemplares, verificou-se, pela Figura 4B, a ocorrência de três picos (dezembro, abril e julho), o que poderia sugerir um padrão com três desovas durante o ano; a ocorrência de uma desova parcelada, no mínimo durante a época reprodutiva, é comum nos Atherinidae (Bemvenuti, 1984).

Contudo, analisando-se a flutuação desse parâmetro em relação às estações do ano (Fig. 4D), verificou-se uma elevação nos valores a partir do outono, época em que o comprimento médio situava-se em torno de $80 \mathrm{~mm}$ (Fig. 4C), e uma queda acentuada foi observada a partir dos meses de inverno, principalmente em julho (Figs 4B e 4D); esse fato, aliado ao tipo de distribuição de freqüência de comprimento apresentado (Figs 3B e 3C), poderia indicar que os exemplares eram oriundos de um mesmo lote de desova, a qual seria única e com início do processo de maturação sexual a partir de julho.

No estuário de São Vicente, Paiva Filho (1982) encontrou exemplares de peixe-rei no estádio $\mathbf{B}$ de maturação gonadal a partir de julho e todos se encontravam no estádio $\mathbf{C}$ em outubro e novembro, correspondendo, neste trabalho, a um tamanho de cerca de $120 \mathrm{~mm}$ (Fig. 4C).

Para Bemvenuti (op.cit.), a espécie iniciou a época reprodutiva em outubro, desovando no verão (novembro a janeiro), com maior intensidade em novembro, sem oscilações temporais do fator de condição e o comprimento de primeira maturação estaria em torno de $100 \mathrm{~mm}$

Possivelmente a desova mais tardia para a espécie residente na Lagoa dos Patos (RS) em comparação com a hipótese do presente estudo, seria uma estratégia reprodutiva, propiciando que as larvas e juvenis encontrassem condiçōes ambientais mais amenas para seu desenvolvimento, evitando as frias temperaturas de inverno características daquela região. 

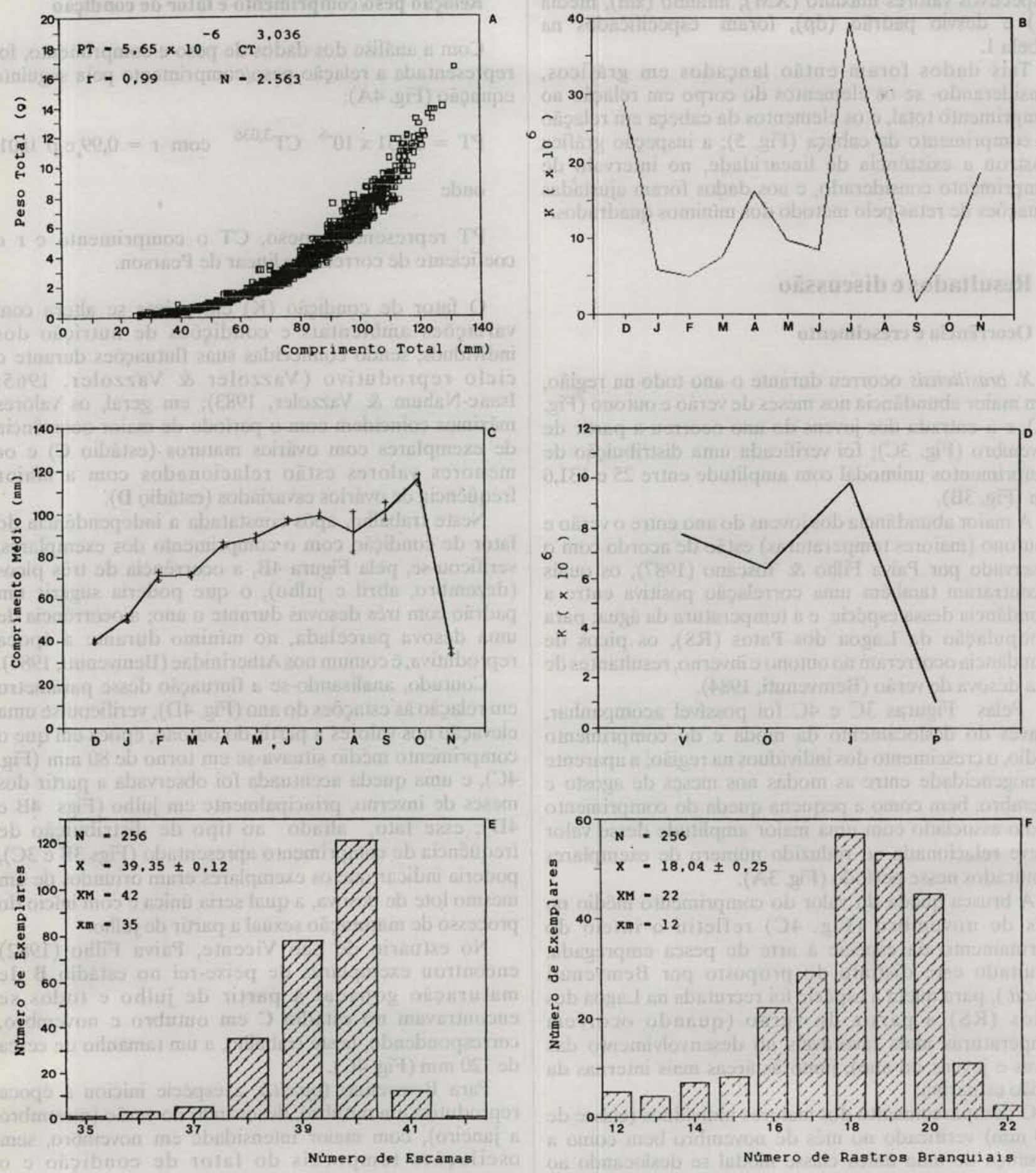

Fig. 4. Representação gráfica da relação peso/comprimento total (A), da flutuação mensal (B) e sazonal (D) do fator de condição alométrico, da flutuaçâo mensal do comprimento médio com $95 \%$ de intervalo de confiança (C), e distribuições de freqüências do número de escamas $(E)$ e do número de rastros branquiais do primeiro arco branquial $(F)$, para todo o período e sexos grupados. $P T=$ peso total em gramas; $\mathrm{CT}=$ comprimento total em $\mathrm{mm} ; \mathrm{r}=$ coeficiente de correlação; $\mathrm{N}=$ número de exemplares usados na regressão; $x=$ média \pm intervalo de $95 \%$ de confiança; $X M$ e xm = maior e menor valores encontrados. 

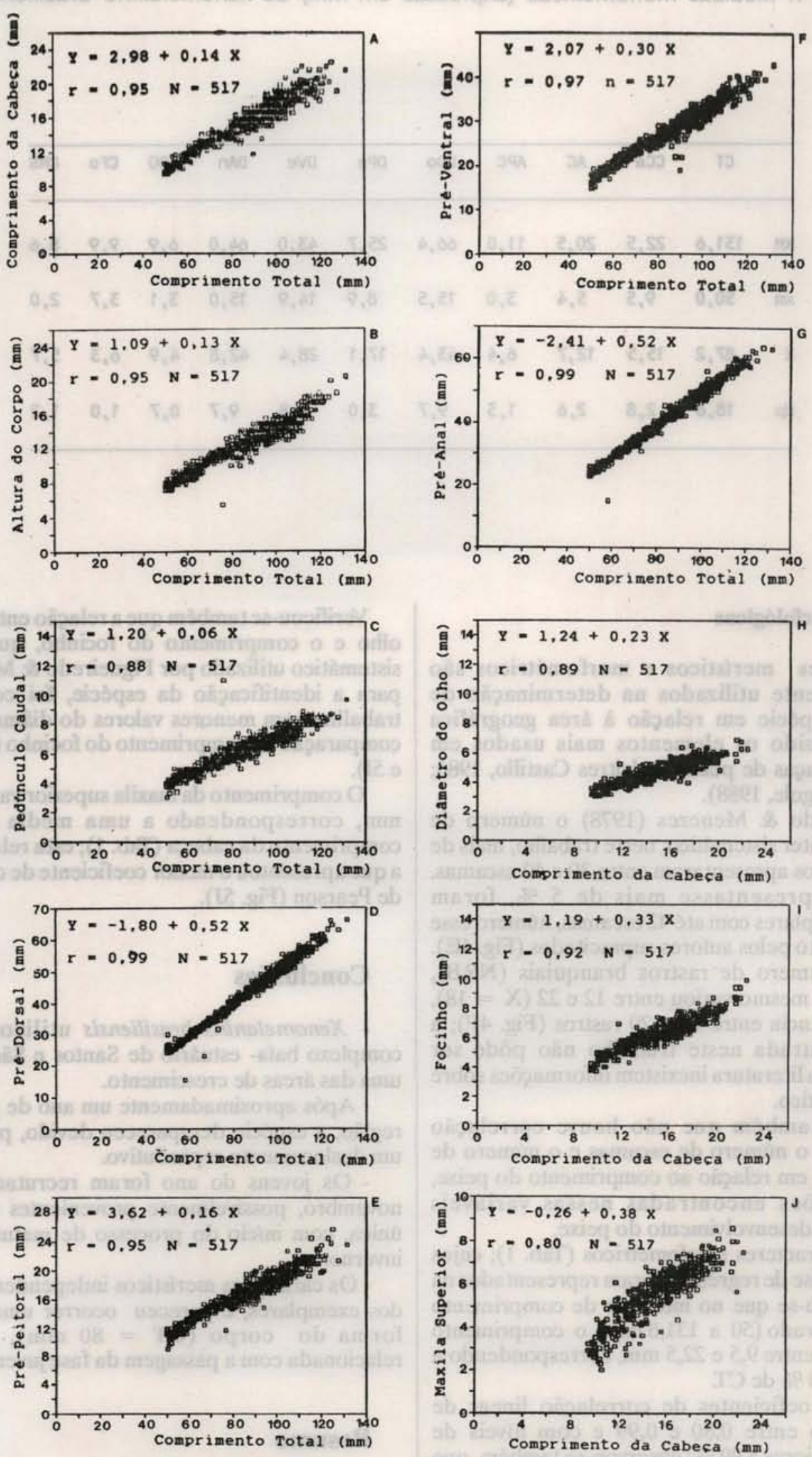

Fig. 5. Representação gráfica das relações entre comprimento total e o comprimento da cabeça $(A)$, altura do corpo (B), altura do pendúnculo caudal (C), distância pré-dorsal (D), distância pré-peitoral (E), distância pré-ventral (F), distância pré-anal (G), entre comprimento da cabeça e o diâmetro do olho $(\mathrm{H})$, comprimento do focinho $(\mathrm{I})$, comprimento da maxila superior $(\mathrm{J})$, para todo o período e sexos grupados. $\mathrm{r}=$ coeficiente de correlação; $\mathrm{N}=$ número de exemplares usados na regressão. 
Tabela 1. Medidas morfométricas (expressas em $\mathrm{mm}$ ) de Xenomelaniris brasiliensis

\begin{tabular}{|c|c|c|c|c|c|c|c|c|c|c|c|}
\hline & CT & $\mathrm{CCa}$ & $A C$ & APC & DDO & $\mathrm{DPe}$ & DVe & DAn & DO & CFo & CMS \\
\hline $\mathrm{XM}$ & 131,6 & 22,5 & 20,5 & 11,0 & 66,4 & 25,7 & 43,0 & 64,0 & 6,9 & 9,9 & 8,6 \\
\hline$x \mathrm{~m}$ & 50,0 & 9,5 & 5,4 & 3,0 & 15,5 & 8,9 & 14,9 & 15,0 & 3,1 & 3,7 & 2,0 \\
\hline$x$ & 87,2 & 15,5 & 12,7 & 6,4 & 43,4 & 17,1 & 28,4 & 42,8 & 4,9 & 6,3 & 5,7 \\
\hline$\phi$ & 18,6 & 2,8 & 2,6 & 1,3 & 9,7 & 3,0 & 5,8 & 9,7 & 0,7 & 1,0 & 1,2 \\
\hline
\end{tabular}

\section{Caracteres morfológicos}

Os caracteres merísticos e morfométricos são aspectos geralmente utilizados na determinação de variaçōes da espécie em relação à área geográfica ocupada e têm sido os elementos mais usados em pesquisas sobre raças de peixes (Alvitres Castillo, 1986; Paiva Filho \& Cergole, 1988).

Para Figueiredo \& Menezes (1978) o número de escamas é um caráter sistemático; neste trabalho, mais de $80 \%$ dos indivíduos apresentaram entre 39 e 40 escamas. Embora nāo representasse mais de $5 \%$, foram encontrados exemplares com até 42 escamas, número esse superior ao descrito pelos autores supracitados (Fig. 4E).

Quanto ao número de rastros branquiais (NRB), verificou-se que o mesmo variou entre 12 e $22(X=18)$, com maior ocorrência entre 18 e 20 rastros (Fig. 4F); a amplitude encontrada neste trabalho não pôde ser discutida, já que na literatura inexistem informaçōes sobre esse caráter merístico.

Verificou-se também que não houve correlação significativa entre o número de escamas e o número de rastros branquiais em relação ao comprimento do peixe, e assim, variações encontradas nessas variáveis independeram do desenvolvimento do peixe.

Quanto aos caracteres morfométricos (Tab. 1), cujos resultados da análise de regressão foram representados na Figura 5, observou-se que no intervalo de comprimento total (CT) considerado (50 a 131,6 mm), o comprimento da cabeça variou entre 9,5 e $22,5 \mathrm{~mm}$, correspondendo a uma média de $17,8 \%$ de CT.

Verificou-se coeficientes de correlaçāo linear de Pearson variando entre 0,80 e 0,99 e com níveis de significância superiores a $99 \%$; observou-se também, que pareceu ocorrer uma alteração na forma do corpo a partir de $80 \mathrm{~mm}$ de comprimento total (Figs $5 \mathrm{~A}$ a $5 \mathrm{G}$ ), demonstrada pela maior amplitude dos valores das variáveis em relação ao comprimento total. Essa mudança poderia estar relacionada com a passagem da fase juvenil para a fase adulta, conforme sugerido por Martin (1949).
Verificou-se também que a relação entre o diâmetro do olho e o comprimento do focinho, que é um caráter sistemático utilizado por Figueiredo \& Menezes (op. cit.) para a identificação da espécie, foi confirmada neste trabalho, com menores valores do diâmetro do olho em comparação ao comprimento do focinho (Tab. 1 e Figs 5H e 5I).

O comprimento da maxila superior variou entre 2 e 8,6 $\mathrm{mm}$, correspondendo a uma média de $36,6 \%$ do comprimento da cabeça (Tab. 1); esta relaçāo foi também a que apresentou o menor coeficiente de correlação linear de Pearson (Fig. 5J).

\section{Conclusões}

- Xenomelaniris brasiliensis utilizou a região do complexo baía- estuário de Santos e São Vicente como uma das áreas de crescimento.

- Após aproximadamente um ano de permanência na regiáo, a espécie desapareceu devido, provavelmente, a um deslocamento reprodutivo.

- Os jovens do ano foram recrutados a partir de novembro, possivelmente provenientes de uma desova única, com início do processo de maturação sexual no inverno.

- Os caracteres merísticos independeram do tamanho dos exemplares, e pareceu ocorrer uma alteração na forma do corpo (CT $=80 \mathrm{~mm}$ ), possivelmente relacionada com a passagem da fase juvenil para a adulta.

\section{Resumo}

Através de um programa de amostragem com arrastos de praia no complexo baía-estuário de Santos e São Vicente, de dezembro de 1984 a novembro de 1985, foram capturados 2.632 exemplares do peixe-rei Xenomelaniris brasiliensis. Neste trabalho foram analisados a ocorrência, 
o crescimento, a relação peso / comprimento, o fator de condição e caracteres merísticos e morfométricos.

$X$. brasiliensis foi capturada durante todo o ano na região, sendo mais abundante no verão e outono; a distribuiçâo foi unimodal e o maior exemplar capturado mediu 131,6 mm. O recrutamento dos juvenis à arte de pesca utilizada teve início no final da primavera, possivelmente relacionado com uma desova de inverno.

\section{Agradecimentos}

Os autores expressam seu agradecimento a Oscar Barbosa e Edgar Borges, da Base de Santos do Instituto Oceanográfico da Universidade de Sảo Paulo, pelo auxílio nos trabalhos de campo.

Às estagiárias Kikue Yamaguchi e Sonia Elisabeth Florence pelo trabalho de campo e de laboratório e à Roberto Ribas Gallucci e Márcia Takatsuka, pelo auxílio na digitação dos dados.

\section{Referências bibliográficas}

ALVITRES CASTILLO, V.R. 1986. Estudo sobre a biologia e ciclo de vida de Menticirrhus americanus (Linnaeus, 1758)(Ubatuba 2330'S - Cananéia $25^{\circ}$ 05'S, São Paulo). Dissertaçāo de mestrado. Universidade de São Paulo, Instituto Oceanográfico. 150p.

BEMVENUTI, M. de A. 1984. Abundância, distribuição, reprodução e hábitos alimentares de peixes-rei (Atherinidae) na região estuarial da Lagoa dos Patos, R.S. Brasil. Dissertação de mestrado. Universidade do Rio Grande. 93p.

CARVALHO, J. de P. 1953. Alimentação de Xenomelaniris brasiliensis (Quoy \& Gaimard) (Pisces-Mugiloidei-Atherinidae). Bolm Inst. oceanogr., S Paulo, 4(1/2):127-144.

CHAO, L.N.; PEREIRA, L.E. \& VIEIRA, J.P. 1985. Estuarine fish community of the Patos Lagoon, Brazil. A baseline study. In: Yáñez-Arancibia, A. ed. Fish community ecology in estuaries and coastal lagoons: towards an ecosystem integration. Mexico, D.F., UNAM Press. p.429-450.
FIGUEIREDO, J. L. \& MENEZES, N. A. 1978. Manual de peixes marinhos do sudeste do Brasil. II. Teleostei (1). Sāo Paulo, Museu de Zoologia da Universidade de São Paulo. 110p.

ISAAC-NAHUM, V.J. \& VAZZOLER, A.E.A. de M. 1983. Biologia reprodutiva de Micropogonias furnieri (Desmarest, 1823) (Teleostei, Sciaenidae). 1. Fator de condição como indicador do período de desova. Bolm Inst. oceanogr., S Paulo, 32(1):63-69.

MARTIN, W.R. 1949. The mecanics of environmental central of body form in fishes. Publs Ot. Fish. Res. Lab., (70):1-91.

PAIVA FILHO, A.M. 1982. Estudo sobre a ictiofauna do Canal dos Barreiros, Estuário de Sāo Vicente, SP. Tese de livre- docência. Universidade de São Paulo, Instituto Oceanográfico. 189p.

\& CERGOLE, M.C.1988.Diferenciação geográfica de Nebris microps (Cuvier, 1830), na costa sudeste do Brasil. Bolm Inst.oceanogr., S Paulo, 36(1/2):37-45.

\section{; GIANNINI, R.; RIBEIRO}

NETO, F.B. \& SCHMIEGELOW, J.M.M. 1987. Ictiofauna do complexo baía-estuário de Santos e Sāo Vicente, SP, Brasil. Relat. int. Inst. oceanogr. Univ. S Paulo, (17): 1-10.

\& TOSCANO, A.P. 1987. Estudo comparativo e variaçāo da ictiofauna na zona entre-marés do Mar Casado-Guarujá e Mar Pequeno-São Vicente, SP. Bolm Inst. oceanogr. S Paulo, 35 (2):153-165.

VAZZOLER, A.E.A. de M. \& VAZZOLER, G. 1965. Relation between condition factor and sexual development in Sardinella aurita (Cuv. \& Val.). Anais Acad.bras.Ciênc., 37(supl.):353-359.
(Recebido em 24-04-89; aceito em 27-06-90) 